\title{
The Effect of Adenotonsillectomy on Korean Children's Voice
}

\author{
Geun Hyung Park ${ }^{1}$, Soon Bok Kwon ${ }^{2}$, Tae Kyung Koh ${ }^{1}$ D , Soo Kweon Koo ${ }^{1}$, \\ Sang Hoon Lee ${ }^{1}$, Ho Byung Lee, and Chang Lok Ji ${ }^{1}$ \\ ${ }^{I}$ Department of Otorhinolaryngology-Head and Neck Surgery, Busan Saint Mary's Hospital, Busan; and \\ ${ }^{2}$ Department of Language and Information, College of Humanities, Pusan National University, Busan, Korea
}

\section{편도 및 아데노이드 절제술이 한국 소아의 음성에 미치는 영향}

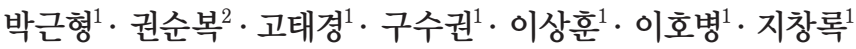

부산성모병원 이비인후과, ${ }^{1}$ 부산대학교 인문대학 언어정보학과 ${ }^{2}$

\author{
Received March 4, 2019 \\ Revised April 22, 2019 \\ Accepted June 3, 2019 \\ Address for correspondence \\ Tae Kyung Koh, MD, PhD \\ Department of Otorhinolaryngology- \\ Head and Neck Surgery, \\ Busan Saint Mary's Hospital, \\ 25-14 Yongho-ro 232 beon-gil, \\ Nam-gu, Busan 48575, Korea \\ Tel $+82-51-933-7214$ \\ Fax +82-51-956-1956 \\ E-mail ktk0305@hotmail.com
}

Background and Objectives Adenotonsillectomy is a commonly performed surgical procedure carried out by otolaryngologists for children. Anatomical changes to the vocal tract occur after the surgery and may alter the patient's voice. This study evaluated the effects of adenotonsillectomy on the voice in Korean children.

Subjects and Method A total of 20 children who underwent adenotonsillectomy were enrolled. The speech of patients was recorded before and at one month of the surgery and acoustic features, especially the formant frequency, were analyzed. Perceptual analysis was also carried out and the Pediatric Voice Handicap Index (PVHI) questionnaire was used to assess subjective changes in the children's voice and the effects of these changes on social functions. Results Acoustic analysis revealed significant decreases in the vowel /i/ in the second formant, compact-diffuse, and grave-acute features of the voice $(p=0.026,0.022$, and 0.031 , respectively). A significant decrease was also observed in the intensity of the voice for the vowel $/ \mathrm{u} /(p=0.025)$. Perceptual analysis revealed that $86.6 \%$ of patients' voice recordings had postoperative changes. The mean preoperative PVHI score was $2.70 \pm 3.37$, which decreased to $1.65 \pm 2.21(p=0.011)$ after the surgery.

Conclusion The results suggest that adenotonsillectomy affects Korean children's voices both acoustically and perceptually.

Korean J Otorhinolaryngol-Head Neck Surg 2019;62(11):637-41

Key Words Child Korea $\cdot$ Tonsillectomy $\cdot$ Voice.

\section{Introduction}

Adenotonsillectomy is the most commonly performed operation in children within the field of otorhinolaryngology. ${ }^{1)}$ Postoperative complications include bleeding, pain, and vocal changes, etc. Among them, changes to the voice after surgery often occur.

This is an Open Access article distributed under the terms of the Creative Commons Attribution Non-Commercial License (https://creativecommons.org/licenses/by-nc/4.0) which permits unrestricted non-commercial use, distribution, and reproduction in any medium, provided the original work is properly cited.
Fant $^{2)}$ presented the source-filter theory in the acoustic theory of speech production. According to this theory, the human voice is produced through the larynx and vocal tract. The human vocal tract includes the oral, nasal, pharyngeal, and laryngeal cavities, which are important resonant cavities. Among them, the space within the oral and laryngeal cavities can be changed freely; thus, these cavities can create various resonance changes. Therefore, changes to the resonance properties after removal of the tonsils and adenoids located in the oral and nasal cavities may affect the voice. In children, in 
particular, the tonsils and adenoids occupy a relatively large area of the oral and nasal cavities and therefore have a large influence on the voice, because the vocal organs are in the process of growth and have yet to undergo voice mutation. Therefore, tonsillectomy or adenoidectomy, which changes the resonance energy in children, is important for childhood voice. Previous studies have produced conflicting results. Some have reported that the postoperative voice will be improved and others have reported that tonsillectomy has little effect on the voice, while others have reported that it can lead to velopharyngeal insufficiency. ${ }^{1,3-6)}$ These conflicting results may have resulted from the inclusion of different languages or a variety of methods for evaluating the voice. Therefore, our study explored vocal changes in a homogeneous population: Korean children who underwent adenotonsillectomy.

\section{Subjects and Method}

\section{Patients}

Our prospective study involved 20 pediatric patients with tonsillar (with or without adenoid) hypertrophy. One patient was diagnosed as having chronic tonsillitis with tonsillar hypertrophy. The study population included 13 boys and 7 girls, with a mean age of 7.6 years (Table 1). The inclusion criteria for this study were palatal tonsillar hypertrophy grade III or IV according to the scale suggested by Brodsky ${ }^{7)}$ and adenoid hypertrophy with $70 \%$ or more nasopharyngeal obstruction. Tonsillar hypertrophy was diagnosed by endoscopic direct observation and X-rays (lateral soft tissue neck view). Patients with a craniofacial or neurological syndrome and those with tonsillar tumors were excluded. We also excluded children who had definitive speech disturbances such as hoarseness, vocal paralysis, vocal fold polyps, laryngeal papilloma, airway infections, and children receiving speech therapy prior to surgery. Informed consent was obtained from all participants. This study was approved by the Institutional Review Board of Busan Saint Mary's Hospital (approval no. BSM 2018-02).

Table 1. Demographic data on children undergoing tonsillectomy \pm adenoidectomy

\begin{tabular}{lc}
\hline & The patients $(\mathrm{n}=20)$ \\
\hline Boy $(\mathrm{n})$ & 13 \\
Girl $(\mathrm{n})$ & 7 \\
Age (mean \pm standard deviation) & $7.6 \pm 2.4$ \\
Tonsillectomy+adenoidectomy $(\mathrm{n})$ & 19 \\
Tonsillectomy $(\mathrm{n})$ & 1 \\
\hline
\end{tabular}

\section{Tonsillectomy and adenoidectomy}

Tonsillectomy and bleeding control were performed using monopolar and bipolar cautery (Conmed Sabre 2400 Electrosurgical Unit; SOMA Technology Inc., Bloomfield, CT, USA) and adenoidectomy was performed using EVAC coblation (Coblator II Surgical System; ArthroCare Corp., Austin, TX, USA) via the transoral approach. All operations were performed by a single operator under general anesthesia.

\section{Voice recordings (data collection)}

Recordings were collected in a noise-controlled room on the day before surgery and at one month after surgery. Each subject was asked to phonate a Korean vowel, /a/, /i/, /u/, and four Korean sentences (이분은 아버지입니다/ibun-eun abeojiibnida/, 이것은 이발소입니다/igeos-eun ibalsoibnida/, 이것은 우체국입니다/igeos-eun uchegug-ibnida/, 우리 더불어서 책 을 펴 봅시다/uli deobul-eoseo chaeg-eul pyeo bobsida/) at a comfortable volume. The voice was recorded at a sampling rate of $192 \mathrm{kHz}$ and recording was performed using a voice recorder (ICD-SX 2000; Sony Co., Tokyo, Japan) with the patient placed at a distance of $20 \mathrm{~cm}$ from the microphone.

\section{Acoustic analysis}

The recorded voice was analyzed acoustically using the Praat software (ver. 5.2.16; University of Amsterdam, Amsterdam, the Netherlands). The number of decibels and the F1, F2, F3, and F4 formant frequencies of each vowel were measured. Other parameters of the vowel structure including the compact-diffuse (CD) and grave-acute (GA) features were also calculated from the formant frequency. The $\mathrm{CD}$ feature was obtained by subtracting F1 from F2. The GA feature was obtained by averaging the two values. According to the distinctive feature theory, the CD feature is regarded as an indicator of tongue elevation, while the GA feature is regarded as an indicator of tongue advancement. ${ }^{8)}$ Changes after surgery were evaluated by comparing the mean values of each parameter.

\section{Perceptual analysis}

Five otolaryngologists listened to and evaluated each patient's voice before and at one month after adenotonsillectomy. Vowels and sentences were scored as 0 (no change), 1 (some change), and 2 (significant change) according to the degree of voice change after surgery (Table 2). ${ }^{9}$

\section{Parental questionnaire}

Before and at one month after surgery, caregivers were asked 
Table 2. Perceptual analysis protocol

\begin{tabular}{cl}
\hline Score & Perception of vowel \\
\hline 0 & No difference \\
1 & A little difference \\
2 & A lot of difference \\
\hline
\end{tabular}

to complete a questionnaire to measure the subjective effects of voice disorders. The Pediatric Voice Handicap Index (PVHI) consists of 23 questions and is divided into functional, physical, and emotional sections containing 7, 9, and 7 questions, respectively. We used the Korean version that has been validated for Korean children. ${ }^{10)}$ Answers are scored from 0 to 4 (0: good, 4: very bad), and the minimum and maximum scores are 0 and 92 , respectively.

\section{Statistical analysis}

For the acoustic analysis, the mean values of each pre- and postoperative parameter were compared using a paired t-test. For the perceptual analysis, overall agreement (OA) among the raters was calculated to determine the percentage of identical ratings between raters. The Fleiss kappa value ( $\kappa$ value) was also used to assess the inter-rater reliability of the five raters. Mean values of the pre- and postoperative PVHI scores were compared using the Wilcoxon signed-rank test. The SPSS Statistics ver. 25.0 statistical software package (IBM Corp., Armonk, NY, USA) was used for all statistical analyses. $p$ values $<0.05$ were regarded as statistically significant.

\section{Results}

\section{Acoustic analysis}

In terms of the vowel /a/, the mean values of F1 and F3 had a relatively clear postoperative decrease (the preoperative $\mathrm{F} 1$ and F3 were $968.96 \pm 155.96 \mathrm{~Hz}$ and $3266.06 \pm 428.27 \mathrm{~Hz}$, respectively, whereas the postoperative F1 and F3 were 896.54 $143.87 \mathrm{~Hz}$ and $3019.44 \pm 444.46 \mathrm{~Hz}$, respectively). However, the $p$ value of F1 and F3 did not reach statistical significance ( $p=0.061$ and 0.063 , respectively) (Table 3 ). In terms of the vowel /i/, the mean values of F2 decreased significantly (the preoperative $\mathrm{F} 2$ was $2751.43 \pm 347.22 \mathrm{~Hz}$ and the postoperative F2 was $2464.41 \pm 389.44 \mathrm{~Hz}$ ). CD and GA also decreased significantly (the preoperative CD and GA were $2245.74 \pm 316.95$ and $1628.56 \pm 185.54$, respectively, and the postoperative $C D$ and GA were $1953.89 \pm 399.12$ and $1487.46 \pm 182.44$, respectively). No significant differences were identified in the remaining parameters (Table 3 ). In terms of the vowel $/ \mathrm{u} /$, the
Table 3. Acoustic parameters (intensity in $\mathrm{dB}, \mathrm{F} 1, \mathrm{~F} 2, \mathrm{~F} 3, \mathrm{~F} 4, \mathrm{CD}$, and GA) when phonating /a/, /i/, and /u/

\begin{tabular}{|c|c|c|c|c|}
\hline Vowel & $\begin{array}{c}\text { Speech } \\
\text { parameter }\end{array}$ & Pre-operative & Post-operative & $\begin{array}{c}\mathrm{p}- \\
\text { value* }\end{array}$ \\
\hline \multirow[t]{7}{*}{$/ a /$} & $\mathrm{dB}$ & $77.01 \pm 3.62$ & $75.97 \pm 3.35$ & 0.321 \\
\hline & $\mathrm{F} 1(\mathrm{~Hz})$ & $968.96 \pm 155.96$ & $896.54 \pm 143.87$ & 0.061 \\
\hline & $\mathrm{F} 2(\mathrm{~Hz})$ & $1531.32 \pm 215.07$ & $1522.13 \pm 201.64$ & 0.891 \\
\hline & F3 $(\mathrm{Hz})$ & $3266.06 \pm 428.27$ & $3019.44 \pm 444.46$ & 0.063 \\
\hline & $\mathrm{F} 4(\mathrm{~Hz})$ & $4375.81 \pm 277.14$ & $4199.91 \pm 499.72$ & 0.110 \\
\hline & $C D$ & $562.36 \pm 135.34$ & $625.59 \pm 149.65$ & 0.163 \\
\hline & GA & $1250.14 \pm 170.13$ & $1209.33 \pm 153.45$ & 0.411 \\
\hline \multirow[t]{7}{*}{ /i/ } & $\mathrm{dB}$ & $74.90 \pm 4.94$ & $73.13 \pm 6.61$ & 0.318 \\
\hline & $\mathrm{Fl}(\mathrm{Hz})$ & $505.70 \pm 69.14$ & $510.52 \pm 47.50$ & 0.698 \\
\hline & $\mathrm{F} 2(\mathrm{~Hz})$ & $2751.43 \pm 347.22$ & $2464.41 \pm 389.44$ & $0.026^{\dagger}$ \\
\hline & F3 $(\mathrm{Hz})$ & $3500.18 \pm 309.42$ & $3408.68 \pm 235.31$ & 0.213 \\
\hline & $\mathrm{F} 4(\mathrm{~Hz})$ & $4386.66 \pm 437.10$ & $4385.49 \pm 346.12$ & 0.992 \\
\hline & $C D$ & $2245.74 \pm 316.95$ & $1953.89 \pm 399.12$ & $0.022^{\dagger}$ \\
\hline & GA & $1628.56 \pm 185.54$ & $1487.46 \pm 182.44$ & $0.031^{\dagger}$ \\
\hline \multirow[t]{7}{*}{ /U/ } & $\mathrm{dB}$ & $70.57 \pm 3.81$ & $67.49 \pm 4.93$ & $0.025^{\dagger}$ \\
\hline & $\mathrm{Fl}(\mathrm{Hz})$ & $542.76 \pm 57.75$ & $541.42 \pm 61.24$ & 0.933 \\
\hline & $\mathrm{F} 2(\mathrm{~Hz})$ & $1231.01 \pm 204.85$ & $1222.19 \pm 192.00$ & 0.836 \\
\hline & F3 $(\mathrm{Hz})$ & $2758.99 \pm 460.12$ & $2731.45 \pm 350.65$ & 0.836 \\
\hline & $\mathrm{F} 4(\mathrm{~Hz})$ & $3911.61 \pm 355.58$ & $3991.06 \pm 304.21$ & 0.382 \\
\hline & $C D$ & $688.25 \pm 193.69$ & $680.78 \pm 160.64$ & 0.899 \\
\hline & GA & $886.88 \pm 110.18$ & $881.80 \pm 113.31$ & 0.871 \\
\hline
\end{tabular}

Values are as mean \pm standard deviaton. $*$ mean values of the pre- and post-operative. Acoustic parameters were compared using paired T-test, tstatistically significant difference $(p<0.05)$. $\mathrm{Fl}$ : first formant frequencies, F2: second formant frequencies, F3: third formant frequencies, F4: fourth formant frequencies, CD: compact-diffuse feature, GA: grave-acute feature

Table 4. Result of the perceptual analysis

\begin{tabular}{cc}
\hline Score & Perception of vowel and sentences, $\mathrm{n}(\%)$ \\
\hline 0 & $16(13.3)$ \\
1 & $48(40)$ \\
2 & $56(46.6)$ \\
\hline
\end{tabular}

mean intensity differed significantly (the preoperative intensity was $70.57 \pm 3.81 \mathrm{~dB}$ and the postoperative intensity was $67.49 \pm$ $4.93 \mathrm{~dB}$ ). No significant changes were observed in the remaining parameters (Table 3 ).

\section{Perceptual analysis}

In terms of perceptual changes, $86.6 \%$ of cases were rated as 'significant change' and 'some change.' We classified these two groups together as 'change.' The $\kappa$ value was -0.05 and the OA was 0.75 (Table 4).

\section{PVHI score}

The mean preoperative PVHI score was $2.70 \pm 3.37$; this 
Table 5. Pre- and postop parental questionnaire

\begin{tabular}{lccc}
\hline & Pre-operative & Post-operative & p-value* $^{*}$ \\
\hline PVHI score & $2.70 \pm 3.37$ & $1.65 \pm 2.21$ & 0.011
\end{tabular}

Values are as mean \pm standard deviaton. $*$ mean values of the pre- and post-operative. PVHI score were compared using Wilcoxon signed-rank test. PVHI: the Pediatric Voice Handicap Index

score decreased to $1.65 \pm 2.21$ at 1 month after surgery $(p=0.011)$ (Table 5).

\section{Discussion}

Resonance cavities include the oral cavity, nasal cavity, pharynx, and larynx. Among them, the space within the oral cavity and larynx can be freely transformed, leading to various vocal changes. Removal of the tonsils located on either side of the oral cavity and the adenoids located in the middle portion between the pharynx and nasal cavity causes a change in the resonance cavity after adenotonsillectomy and thus has a huge influence on the voice. This has been of great concern not only to occupational voice users but also to children who are still growing and to the general public.

Several studies have investigated vocal changes associated with tonsillectomy and adenoidectomy. Analysis of formant frequency is a helpful method that can predict changes in the upper airways that act as resonance organs. Previous research has found that variations in F1 reflect airway changes in apneic snorers, whereas variations in F2 reflect changes in the morphology of the tongue and variations in F3 reflect lip movements. ${ }^{11-13)}$ Some recent studies have used objective analysis of formants as well as subjective analyses. Some have reported that F0, F1, and F2 formant frequencies do not change significantly after tonsillectomy with or without adenoidectomy. ${ }^{14-17)}$ In contrast, Lin, et al. ${ }^{18)}$ observed an increase in F0 after surgery, and Kara, et al. ${ }^{19)}$ reported significant changes in F3 and F4 in 36 children at 3 months after adenotonsillectomy.

Our study revealed changes in acoustic characteristics of the voice after adenotonsillectomy. We observed a significant change in formant frequency was only for vowel /i/, which decreased significantly in F2, CD, and GA values. We believe that /i/ is most affected by postoperative tongue position changes because it is a front-high vowel. F2 is mainly dependent on the height of the tongue, $\mathrm{CD}$ is the parameter that reflects the height of the tongue, and GA is the parameter that determines the fore and aft position of the tongue. The oropharyngeal space after surgery becomes widened and causes the tongue to pronounce in the posteroinferior position. $/ \mathrm{u} /$ is a back-low vowel with no significant change in the movement of the tongue. /a/ is a back-high vowel with little fore and aft motion of the tongue. Therefore, these vowels appear not to change after surgery. The change in $\mathrm{dB}$ for the vowel /u/ was statistically significant, where the mean preoperative $\mathrm{dB}$ was $70.57 \pm 3.81$ and the mean postoperative $\mathrm{dB}$ was $67.49 \pm 4.93(p=0.025)$. However, a $3-\mathrm{dB}$ change may not be large enough to be of clinical significance because sound is perceived to be twice as loud for every increase of $10 \mathrm{~dB}$.

Our results differ slightly from those of previous studies, due to the nature of research measuring vocal parameters. The measurement of vocal parameters is highly sensitive, so statistical values vary depending on the selection of subjects and the postoperative follow-up duration.

The degree of tonsillar hypertrophy varies from grade I to grade IV, depending on size. Saida and Hirose ${ }^{14)}$ reported that vocal changes occur when grade III or higher tonsils are removed. Ilk, et al. ${ }^{17)}$ reported that the greater the grade of tonsil, the more severe the change of postoperative voice. Therefore, we included patients with grade III or IV tonsillar hypertrophy. We also limited the age range of subjects, because children under the age of 5 years may not be able to phonate as requested, and children aged 10 years and older may have already experienced voice mutation.

In vocal analysis, perceptual analysis of subjective vocal changes is important. Previous perceptual analyses performed by language pathologists or otolaryngologists have yielded variable results. Chuma, et al. ${ }^{15)}$ reported that the majority of perceptual categories did not change significantly postoperatively, except for a significant decrease in hyponasality. Lunderborg, et al. ${ }^{20)}$ reported that their study population had more hyponasality, compressed/throaty voice, and lower pitch, and that these were significantly improved and normalized after surgery. In our study, we found that most patients had postoperative changes, indicating the possibility of vocal change after surgery. Although the $\kappa$ value was low, the OA was 0.75 , which was highly consistent among raters. However, a particular limitation of our study is that we did not investigate detailed perceptual parameters such as hoarseness, breathiness, nasality, pitch, roughness, etc., and we did not aim to reach a consensus about the definition of 'voice change.'

We used the PVHI to conduct a subjective analysis according to the parents' response. The PVHI is a validated questionnaire for assessing the psychosocial aspects of voice dis- 
orders. Naraghi, et al. ${ }^{21)}$ recruited 86 children aged 3-13 years and reported an improved PVHI score after tonsillectomy with or without adenoidectomy (mean preoperative score: 14.39, mean postoperative score: 2.93). A study that compared the PVHI scores of normal and dysphonic groups of Korean children aged 3-11 years reported a score of 2.33 for the control group (mean age: $7.73 \pm 1.43$ years, $n=15$ ) and 23.13 for a dysphonia group (mean age: $7.33 \pm 2.87$ years, $\mathrm{n}=15$ ) diagnosed with vocal cord nodules. ${ }^{22)}$ In our study, the mean preoperative score was $2.70 \pm 3.37$ and the mean postoperative score was $1.65 \pm 2.21(p=0.011)$. Although the difference before and after surgery was statistically significant, the preoperative PVHI scores of our patients were very similar to those of normal Korean children, and the postoperative PVHI scores were within the normal range. This could not explained may be a placebo effect related to the parents' expectations of a positive change postoperatively. Therefore, this result indicates that, at the least, the parents did not perceive a negative change in their child's voice after surgery.

In conclusion, tonsillectomy with or without adenoidectomy may affect the voice acoustically and perceptually in Korean children. Voice research is highly sensitive, so our study of postoperative vocal changes in Korean children is valuable. When performing adenotonsillectomy, consideration should be given to the possibility that Korean children's voices may be altered after surgery. In the future, it will be necessary to study more diverse subject groups, use various research methods, and allow a longer follow-up duration for Korean children who undergo adenotonsillectomy.

\section{ORCID}

Tae Kyung Koh https://orcid.org/0000-0002-2805-2270

\section{REFERENCES}

1) Salami A, Jankowska B, Dellepiane M, Crippa B, Mora R. The impact of tonsillectomy with or without adenoidectomy on speech and voice. Int J Pediatr Otorhinolaryngol 2008;72(9):1377-84.

2) Fant G. Acoustic theory of speech production: With calculations based on X-ray studies of Russian articulations. Hague: Mouton;1960. p.15-26.

3) Mora R, Crippa B, Dellepiane M, Jankowska B. Effects of adenotonsillectomy on speech spectrum in children. Int J Pediatr Otorhinolaryngol 2007;71(8):1299-304.

4) Mora R, Jankowska B, Mora F, Crippa B, Dellepiane M, Salami A. Effects of tonsillectomy on speech and voice. J Voice 2009;23(5):
614-8.

5) Tuzuner A, Demirci S, Akkoc A, Arslan E, Arslan N, Samim EE. Nasalance scores in pediatric patients after adenoidectomy. Int $\mathrm{J}$ Pediatr Otorhinolaryngol 2014;78(4):610-3.

6) Celebi S, Yelken K, Celik O, Taskin U, Topak M. Thermal welding vs. cold knife tonsillectomy: A comparison of voice and speech. Int J Pediatr Otorhinolaryngol 2011;75(1):114-7.

7) Brodsky L. Modern assessment of tonsils and adenoids. Pediatr Clin North Am 1989;36(6):1551-69.

8) Jacobson R, Fant G, Halle M. Preliminaries to speech analysis: The distinctive features and their correlates. Cambridge, MA: MIT Press;1969. p.27-37.

9) Lee JH, Koo GJ, Koo HE, Kim YC, Koo SK, Lee SH, et al. An acoustic and radiologic study on voice change after tonsillectomy and adenotonsillectomy. Korean J Otolaryngol-Head Neck Surg 1999;42(6):762-9.

10) Park SS, Kwon TK, Choi SH, Lee WY, Hong YH, Jeong NG, et al. Reliability and validity of the Korean version of pediatric voice handicap index: In school age children. Int J Pediatr Otorhinolaryngol 2013;77(1):107-12.

11) Koo SK, Kwon SB, Kim YJ, Moon JIS, Kim YJ, Jung SH. Acoustic analysis of snoring sounds recorded with a smartphone according to obstruction site in OSAS patients. Eur Arch Otorhinolaryngol 2017;274(3):1735-40.

12) Sundberg J. Level and center frequency of the singer's formant. J Voice 2001;15(2):176-86.

13) Ng AK, Koh TS, Baey E, Lee TH, Abeyratne UR, Puvanendran K. Could formant frequencies of snore signals be an alternative means for the diagnosis of obstructive sleep apnea? Sleep Med 2008;9(8): 894-8.

14) Saida $H$, Hirose $H$. Acoustic changes in voice after tonsillectomy. Acta Otolaryngol Suppl 1996;523:239-41.

15) Chuma AV, Cacace AT, Rosen R, Feustel P, Koltaii PJ. Effects of tonsillectomy and/or adenoidectomy on vocal function: Laryngeal, supralaryngeal and perceptual characteristics. Int J Pediatr Otorhinolaryngol 1999;47(1):1-9.

16) Hori Y, Koike Y, Ohyama G, Otsu SY, Abe K. Effects of tonsillectomy on articulation. Acta Otolaryngol Suppl 1996;523: $248-51$.

17) Ilk HG, Eroğul O, Satar B, Ozkaptan Y. Effects of tonsillectomy on speech spectrum. J Voice 2002;16(4):580-6.

18) Lin P-T, Gould WJ, Fukazawa T, El-Assuooty A. Acoustic analysis of voice in tonsillectomy. J Voice 1989:3(1):81-6.

19) Kara M, Öztürk K, Özer B. An evaluation of the effects of adenoidectomy on voice and speech function in children. Kulak Burun Bogaz Ihtis Derg 2013;23(4):225-31.

20) Lundeborg I, Hultcrantz E, Ericsson E, McAllister A. Acoustic and perceptual aspects of vocal function in children with adenotonsillar hypertrophy--effects of surgery. J Voice 2012;26(4):480-7.

21) Naraghi M, Adil S, Bastaninejad S, Dabiran S. Evaluation of pediatric voice handicap index and pediatric voice related quality of life before and after adenotonsillectomy in pediatric population. Int J Pediatr Otorhinolaryngol 2015;79(3):388-91.

22) Park SS, Choi SH, Hong YH, Jeong NG, Sung MW, Kim KH, et al. Pediatric Voice Handicap Index-Korean(pVHI-K) : A pilot study for standardiztion. J Korean Soc Laryngol Phoniatr. 2011;22(2): $137-42$. 